\title{
An Analysis of Threats to Marine Biodiver- sity and Aquatic Ecosystems
}

\author{
By Sidharta ChatTerjeE* \\ Visiting Researcher, Andhra University \\ Department of Social Work, Visakhapatnam, India \\ Email: sidharta1230yahoo.com
}

May 3, 2017

\begin{abstract}
Marine ecosystems and aquatic habitats face a number of threats from humans. Serious conservation attention and efforts should be drawn and directed towards restoration of fragmented marine habitats and estuarine ecosystems. Threats are manifold: i.e., primarily from overexploitation of marine resources, overfishing, climate warming, sewage disposal, industrial chemical discharge, oil spills, invasive species, and dredging. The Corals are particularly fragile animals and very sensitive to changes in temperature and salinity. Coral reefs are coastal habitats build by corals that are also one of the most productive habitats within the marine ecosystems, but they are however, at great danger of going extinct from any drastic changes in sea surface temperature and salinity. Ecosystem services provided by coastal areas helps to sustain coastal people whose livelihood depends on fishing and fish products, aquaculture and exploitation of biologically diverse resources that the seas and the oceans provide them. For this reason, it is essential to monitor marine biodiversity and prevent further degradation of marine habitats. This paper attempts to address this critical issue to stimulate conservation efforts among policy makers and ecologists. Besides, it is also relevant to understand how ecosystem gets degraded, and what measures are best and should be undertaken to prevent further degradation of marine habitats.
\end{abstract}

Keywords: Marine biodiversity, ecosystem services, habitat destruction, coral bleaching, coral reefs, IUCN

\section{Introduction}

Biodiversity is the sumtotal of richness and variation of all living things. It represents variability among living organisms that include marine, terrestrial and aquatic ecosystems. Of these, the marine ecosystem represents the most biologically diverse bionetwork of flora and fauna which is still largely unexplored. Such diversity is a provider of economic services which comes as a blessing to coastal people (MoE Report 2011). However, marine ecosystems are under pressure and the global bio-

*. Corresponding author.

Disclaimer: Views expressed in this paper are those of author's, and do not necessarily represent the views of Andhra University of any other entity. 
diversity is threatened. These presents as broad-scale threats to marine biodiversity (Helm and Hepburn 2014; Mapstone 2010; Imtiyaz, Sweta and Prakash 2011). Broadly, such threats can be categorized as follows (Nevill, 2008):

i. Climate change induced Global warming

a) Physical changes: change in sea water surface temperature

b) Chemical changes: change in salinity

ii. Habitat destruction

a) Commercial exploitation and dredging activities,

b) Destruction of Coral habitats

c) Habitat damage from bottom trawling

iii. Problem of overfishing and bycatch

a) Illegal fishing, bycatch problems

b) Unregulated and overfishing

iv. Pollution from sewage disposals which include harmful chemicals

a) Hazardous pollutants (includes toxic and radioactive chemicals etc.)

b) Sewage litters (e.g., plastic, inorganic debris, cans etc.)

The threats to global biodiversity (See also Sechrest and Brooks 2002) and marine ecosystems are real (Casper 2010), because marine habitats are fragile. Marine ecosystems are highly responsive to fluctuations and changes in physical environments (Pan et al. 2013) while at the same time, they are resilient and adaptable to such changes (Steele 1998). Like terrestrial ecosystems, marine ecosystems and habitats are susceptible to destruction (Walker and Kendrik 2006), pollution and climate warming (Craig 2012, Walker and Kendrik 2006). Coastal ecosystems are also prone to destruction due to high population pressure and construction of port facilities, marinas and other logistic amenities (Burke et al., WRI Report 2001, Ólafsson 2017). Unquestionably, expansion of human activities threatens ocean-wide biodiversity (Dulvy et al. 2014). Continuous dredging causes damage to riverine and estuarine ecosystems. Furthermore, marine wildlife and ecosystems of the polar regions are susceptible to the impacts of climate warming and enhanced anthropogenic activities. In simple words, coastal biodiversity is at risk and marine environments are threatened (Imtiyaz, Sweta and Prakash 2011) from heightened human activities (Dulvy et al. 2014). It may not be reasonable to reduce coastal human activities, but it may be feasible to think about means and methods to reduce further damage to coastal ecosystems. The goal of this paper, therefore, is to address these critical issues regarding conservation of coastal and marine ecosystems and advocate effective strategies, and convert those into actions. Furthermore, this research analyzes the importance of habitats and why habitats are essential for propagation and survival of species. The analytic model simply reinforces the significance of habitat quality and the effect of habitat protection on the survival of species. 


\section{Ecosystem Services}

Marine ecosystems provide many essential services - as for example, food resources for millions of people. Ecosystem services (Cowling et al. 2008) provided by marine environments and coastal areas are varied in nature. These can be enumerated as (adapted from Burke 2001):

i. Fish and fisheries for food production

ii. Maintenance of Biodiversity

iii. Tourism and recreation

iv. Marine transport and port facilities

v. Shoreline stabilization

vi. Water quality

vii. Hydrologic functions

There are other services provided by marine ecosystems for instance; deep sea oil exploration and drilling, mining for minerals, etc. In a nutshell, biodiversity plays a positive role in maintaining the ecosystem services which supports a growing human population (Worm et al. 2006). However, marine ecosystems are facing accelerating loss of aquatic species and they are threatened by various anthropogenic activities that are damaging to marine habitats. Habitat loss can lead to decline in ecosystem services (Dobson et al. 2006). Although the immediate consequences are not known, such accelerated loss of marine species could impact smooth flow of ecosystem services in the long term.

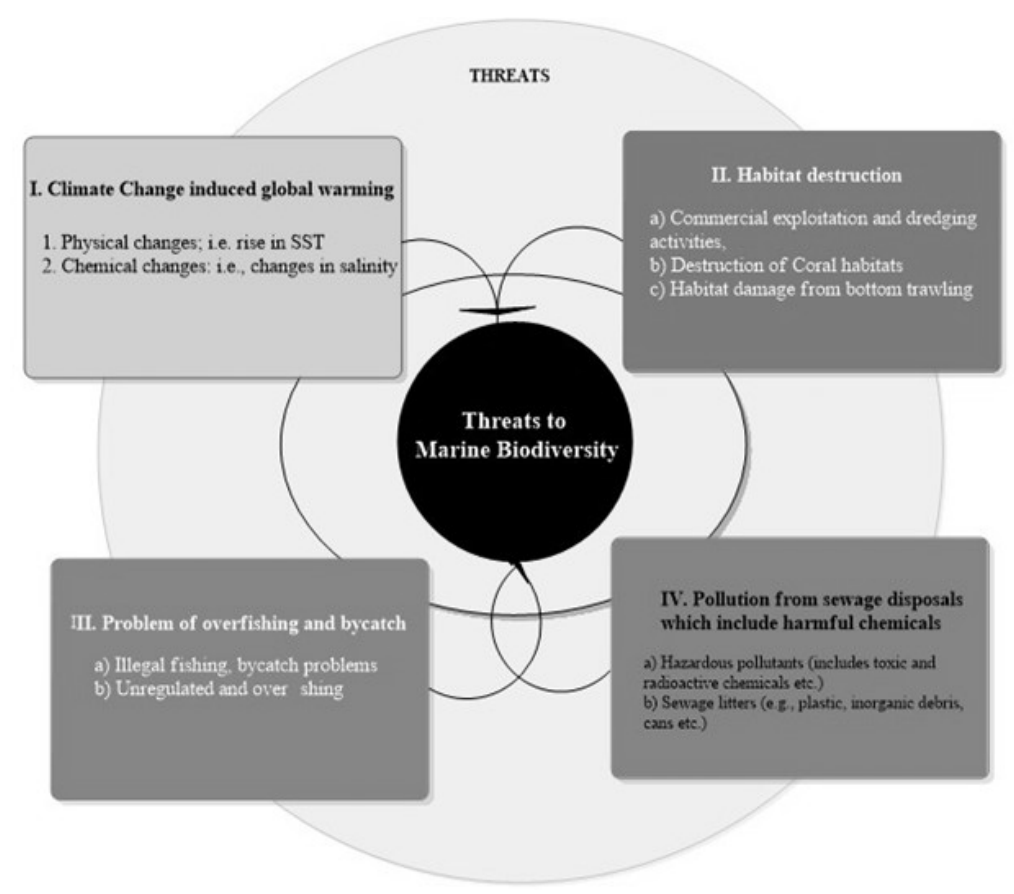

Figure 1. Major threats to marine biodiversity 
Damage to coastal ecosystems has economic implications as well. The economic value of coastal ecosystems depends on the marine biological diversity. Ocean biodiversity loss affects ecosystem services (Worm et al. 2006). Marine species are largely dominated by arthropods (phylum crustaceans), molluscs and fish. Economic value of fishes are well acknowledged - they are the sources of food and nutrition for millions of people. Besides, the phylum crustaceans which include crabs, crayfish, shrimp, prawns and lobsters have immense economic value. They are mostly found along the coastlines of seas and oceans. The coastlines of seas and oceans are therefore, biologically active areas of productivity, and they represent a substantial share of economic activities for the coastal people. The business of mariculture (seaweeds) is also an important contributor to ecosystem services. Beyond doubt, erosion of biodiversity has definite impact on humanity (MA 2005, Cardinale et al. 2012, Worm et al. 2009). Therefore, the ongoing erosion of marine biodiversity could have economic and ecological implications in the long run.

\section{Marine Biodiversity under Threat}

It is now evident that there are many marine species including some marine animals and mammals which are threatened, endangered or vulnerable to climate change and susceptible to being severely affected by augmented human activities. Some marine species have already become extinct (See Estes, Burdin and Doak, 2015), while some others - for instance, polar bear (Ursus maritimus), is facing risk of extinction from the melting Arctic ocean ice due to climate warming (Hunter et al. 2010). The World Conservation Union (IUCN) monitors species diversity across regions. It maintains a list-The IUCN Red List (Rodríguez et al. 2015) which specifies the degree of abundance or scarcity of plants and animal species by assigning measurable categories to describe their relative occurrence in a particular region. To put it simply, IUCN Red List is an approach for monitoring and assessing the status of global biodiversity ${ }^{1}$. This has important implications; e.g., the Threatened species are candidates for protection and conservation, whereas the Endangered species are candidates for close observation as well as protection.

Biodiversity loss threatens human well-being (Díaz et al. 2006). With an unprecedented rate of biodiversity loss, the uninterrupted provision of goods and services from marine ecosystems are threatened. So it is important to evaluate the loss of biodiversity at the ecosystem level. Of importance to note, biodiversity is a dominant driver of ecosystem productivity (Tilman, Reich and Isbell 2012). Marine ecosystems are highly productive, and there is a positive relationship between diversity and ecosystem functions and services (Worm et al. 2006). However, valuation of biodiversity is a difficult and tricky job (See Nunes and van den Bergh 2001). It is easy to assume the impact of biodiversity on human welfare, but it is rather difficult to perform a valuation analysis of all the possible indicators of ecosystem services.

1. See Baillie, J.E.M., Hilton-Taylor, C. and Stuart, S.N. (Editors) 2004. 2004 IUCN Red List of Threatened Species. A Global Species Assessment. IUCN, Gland, Switzerland and Cambridge, UK. 
It is because ecosystem functions (Odum 1971) are varied, and so it may not be easy to perform a valuation of life support functions that ecosystems provide which include provision of clean air, healthy environment, and carbon storage (Nunes et al. 2000). However, valuation of biodiversity loss could be an alternative approach as an economic indicator of the loss of biological products and services flows. It is particularly relevant to Coral biodiversity and coastal ecosystems. Local degradation and loss of habitat for marine flora and fauna may reduce the overall ecosystem services being provided by the coastlines. The value of Ecosystem services - which according to some estimate (Boesch 1999), amounts to around $\$ 21$ trillion a year, wherein, coastal systems contribute $63 \%$ of this total amount. According to another estimate, world's coral reefs produces goods and services worth of economic value $\$ 29.8$ billion per year. Of this amount, tourism accounts for $\$ 9.0$ billion, and fisheries $\$ 5.7$ billion (Conservation International, 2008). So, loss of coral reefs would also result in loss of substantial ecosystem services. Obliteration of coral reefs may also result in loss of aesthetic beauty of many shallow shorelines. Destruction of coral reefs follow coral bleaching, and scientists know how exactly this happens. Corals have low physiological tolerance to high temperature. Therefore, one of the biggest enemy of corals is global warming. Coral bleaching ${ }^{2}$ results from high stress factors such as rising or falling temperatures, intense light, low salinity (ocean acidification) all of which causes loss of endosymbionts (zooxanthellae).

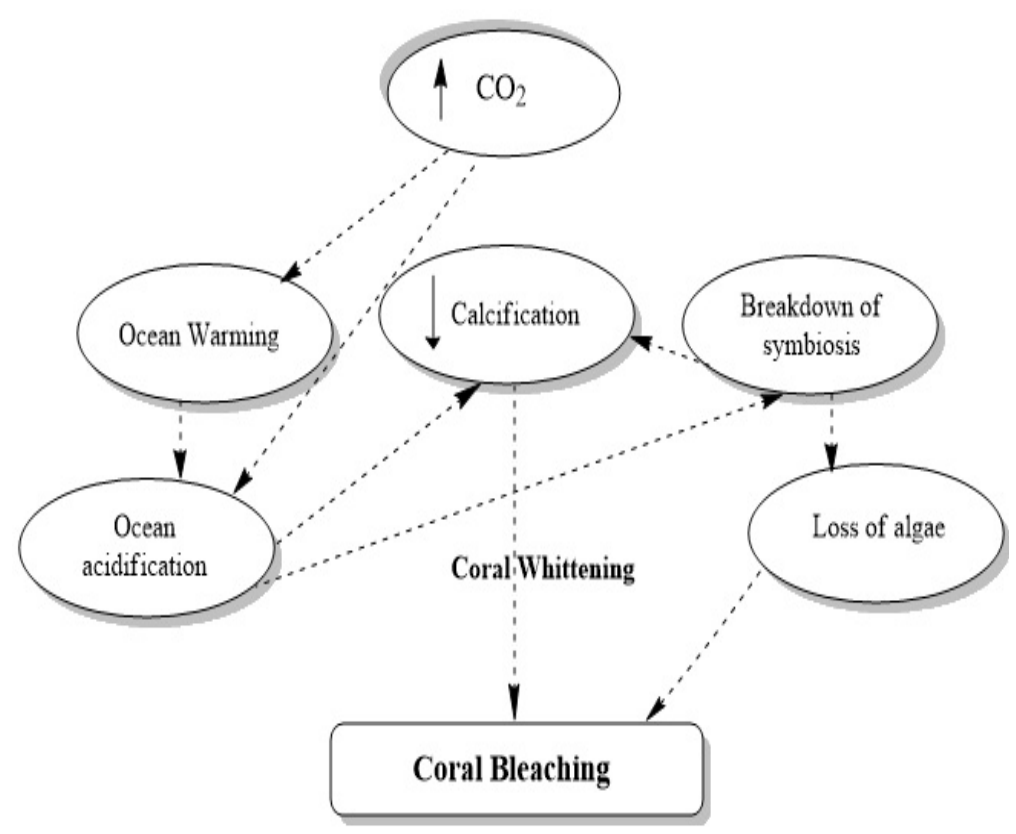

Figure 2. Mechanism of Coral Bleaching

Corals are temperature sensitive; rise in sea surface water temperature by only

2. See for example, Brown B., 1997; Coral Bleaching: Causes and Consequences. Coral Reefs 16, S129S138. 
$1.1^{\circ} \mathrm{C}$ can initiate the bleaching effect (see Fig.1) which if prolonged, will result in death of corals (See Veron et al. 2009 ). In fact, the ecosystems most threatened by climate change are coral reefs (McClenachan et al. 2007). Several incidents of coral bleaching (Brown 1997, Eakin et al. 2016) are on record (see for example, "Global bleaching episode", NOAA ${ }^{3}$ 1998, 2010, and 2015). Although bleaching itself does not always lead to mass mortality of corals (Eakin CM et al. 2010), nevertheless, climate anomalies have been linked to coral bleaching (Glynn 1990) that resulted in local extinction of coral populations (See Cahill et al. 2012). The fact is, coral reefs around the world are threatened (Eakin et al. 2016). For instance, the Coral Triangle (Hoegh-Guldberg 2009) is home to the greatest number of marine species, and contains $76 \%$ of world's coral species. It is a global centre of marine biodiversity. Coral triangle constitutes much of the Indian Ocean and encompasses Indonesia, Malaysia, The Philippines, Papua New Guinea, Solomon Islands and Timor Leste. However, this epicentre of marine biodiversity faces several threats and challenges. Coral reefs are constituents of coastal ecosystems. They provide critical ecological services. So, it is very important to preserve and device methods to limit further damage to the coastal ecosystems. Besides, the marine biodiversity of India also faces a multitude of challenges since according to the IUCN (Joshi, Varsha and Sruthi 2015), several species are either endangered or threatened. Significant among them is Hawksbill turtle (Eretmochelys imbricata) which is critically endangered, and the well known Bengal Tiger (Panthera tigris tigris), which is endangered. There are several endangered species associated with the Mangroves ecosystems of India (See for instance, Joshi, Varsha and Sruthi 2015).

\section{Importance of Marine Biodiversity}

Marine ecosystems are valuable but vulnerable. They are biologically so diverse that they are home to $97 \%$ of all species on earth (Lefèvre, IUCN Report 2007). It is factual that the oceans and seas support a large number of biologically diverse species which contribute immensely to ecological diversity. Marine species diversity is immense; estimates of known and unknown marine species diversity could be obtained from a compilation by a consortium of scientists, ecologists, conservationists which have been published in Current Biology by Appeltans et al. 2012. They report a total number of $\sim 226,000$ eukaryotic marine species, and speculate that there could be another one third or two thirds of marine species that may be undescribed. Of the total 222,000 - 230,000 marine species described, nearly 200,000 belongs to Animalia (Appeltans et al. 2012).

3. National Oceanic and Atmospheric Administration (NOAA). See NOAA, 2015; NOAA Coral Reef Watch : 2015 Annual Summaries of Thermal Conditions Related to Coral Bleaching for NCRMP Jurisdictions. 


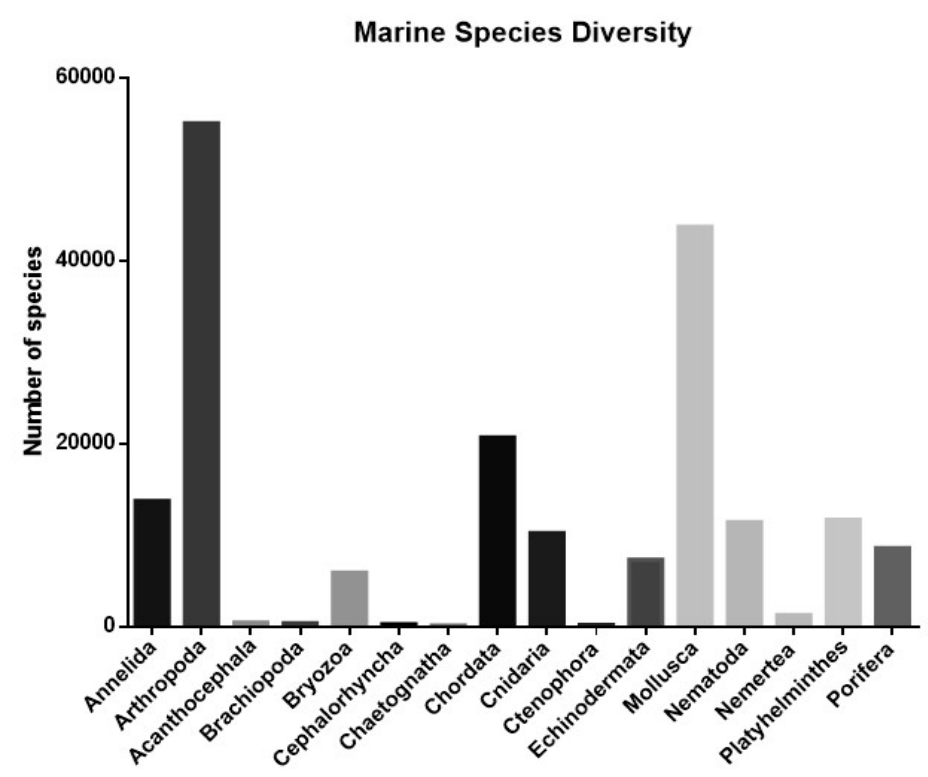

Figure 3. Estimate of marine animal species (See Appeltans et al. 2014: How Many Species in the Ocean?)

Figure 2 above depicts the number of estimated marine animal species as a component of marine biodiversity. It shows the relative contribution of different animal phyla and their relative known or unknown species diversity as computed from Appeltans et al. 2014. Thus, it may not come as a surprise to consider the fact that such a diversity is a ready storehouse of a wide variety of biological resources (products) that could hold immense medicinal or economic value. In fact, marine ecology provides ecosystem services that have economic, biological and non-economic value. These include Fish and fish products, mollusks, seaweeds and algae (sources of phycocolloids ${ }^{4}$ ) which are among the primary sources of ecosystem services. Phycocolloids are polysaccharides derived from seaweeds (Gonçalves et al. 2014) that have applications in food, cosmetic and chemical industries. Therefore, conservation of biodiversity (Hourigan 1999) should be a priority to enable smooth and sustainable flow of ecosystem services, without overexploiting the nature. This requires periodic asessment of marine biodiversity and the impact of human activities on marine ecosystems. The United Nation's The Millennium Ecosystem Assessment (MA) and the Ministry of Environment (MoE 2011) of Japan periodically analyzes the anthropogenic impact on the structure of marine and terrestrial ecosystems.

4. Phycocolloids include algin, alginates, carrageenan etc. These are gelatinous chemicals produced by seaweeds that are used in food processing, as emulsifier, stabilizer and toppings, and in the production of dairy products. Other phycocolloids like for example, ulvan, chitosan, fucoidan, laminarin have many applications. See for instance, Marine Biology: Castro \& Huber, chapter 6: Multicellular Primary Producers: Seaweeds and Plants, 7th edition pg. 109. 


\begin{tabular}{|l|l|l|}
\hline Critically endangered & Threatened & Extinct \\
\hline Alabama cavefish & Rockhopper Penguins & Steller's sea cow \\
\hline Yangtze sturgeon & Paddlefish & Short-barbeled barb \\
\hline Vaquita & Green sturgeon & Syr-Dar shovelnose sturgeon* \\
\hline
\end{tabular}

* Extinct in the wild

Table 1. Source: IUCN Red List

It is necessary to conserve and protect marine biodiversity as much as it is essential to preserve terrestrial and estuarine ecosystems. Identifying the factors that affect marine population dynamics, habitation composition, and stress effect (or constraints) is crucial for effective conservation of marine species. Another important aspect is to monitor how species respond to constraints posed in different types of aquatic ecosystems, for instance, freshwater, estuarine and marine ecosystems. Marine ecosystem is the home to many animals and mammals which also include molluscs, and the largest biomass of green plants occurs in the oceans which happen to be the microscopic algae (phytoplankton ${ }^{5}$ ). However, marine ecology is threatened by elevated sea surface temperature (SST) which could adversely affect coral survival. Survival-extinction dynamics and its outcome depends on the adaptive capacity of a species under stress, as well as on various other factors. Since several exotic and charismatic marine species are threatened with extinction, different conservation focus is required in marine ecosystems (McClenachan et al. 2012) that include oceans and sea. Table 1 shows several marine species that are categorized according to their current status of abundance or scarcity. Table 1 also depicts three extinct species that have been enumerated alongside those that are critically endangered or threatened. The reader is referred to the IUCN Red List $^{6}$ for more detailed information on threatened species.

\section{Methods}

\subsection{Analysis of Ecosystem Threats}

Threats facing aquatic ecosystems and marine habitats are manifold (vide section 1). Owing to extensive human activities, marine biodiversity is at crisis. Illegal overfishing has resulted in a decline in marine animal population. Degradation of marine habitat has resulted in obliteration of coral reefs. This has been compounded by climate warming which has furthermore compromised marine habitats. This section undertakes a systematic analysis of threats to marine biodiversity and the ecosystem. We attempt to model such threats using a simple mathematical representation to study and analyze the current threats to marine ecosystems and their effects on marine life and habitats.

5. Phytoplanktons are microscopic floating plants which are mostly algae. See Encyclopedia of Marine sciences; Baretta-Bekker et. al., (Eds.) pg. 201.

6. IUCN Red List website: http://www.iucnredlist.org 


\subsection{The Model}

We construct a simple model to examine and illustrate the importance of habitat for species survival. For our model, we define the variables as follows: $\eta_{\tau}=$ extinction risk, $\vartheta_{1}=$ species diversity, $x=$ threats, $\lambda=$ habitat, $\rho=$ population, and $\epsilon=$ error term. Habitats are characterized by distribution, range, depth, physiography, zone (i.e., benthic), salinity, etc. The system of equation representing the model can be represented as;

$$
\eta_{\tau}=\vartheta_{1} \times\left(1-\rho^{\lambda}\right)^{x}+\epsilon
$$

By solving equation (1), we derive,

$$
\epsilon+\left(1-\rho^{\lambda}\right)^{x} \times \vartheta_{1}
$$

By plotting equation (2) below, we derive a graphical relationship between species survival and habitat threshold:

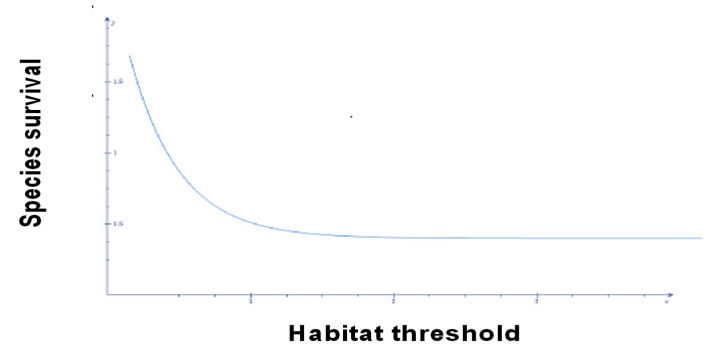

Figure 4.

The area under curve (AUC) in Fig. 4 depicts the optimum habitat threshold for a given species. Habitats determine species diversity. Survival of a species is dependent on habitat quality which is more specific for habitat specialists like for example, corals. Equation (2) defines a scenario of $\max ($ optimum) level of population of different species that could explain the diversity of a given habitat. It also explains that the population density is highly dependent on the habitat quality which strictly affects species diversity of a particular region. There is a certain limit (or extent) to which a reduction in population is sustainable and which do not lead to extinction. A drastic reduction in habitat, however, negatively impacts population density and no other factor could compensate for habitat destruction. So, preservation of habitat and restoration of a fragmented habitat should be the overriding precedence to avoid species loss through extinction. This explains why conservation of habitats are so essential. And finally, to asess whether if a species is threatened or not, there is need for collection of better data on population size and evaluation of the habitats.

\section{Results and Discussion}

Diverse threats threaten marine biodiversity. It is essential to understand the nature and dynamics of such threats to marine biodiversity and undertake proactive measures in order to manage such threats. Goals should be directed towards conservation of marine biodiversity (Jone, Srinivasan and Almany 2007) by undertaking activities that are beneficial to marine habitats. The analytic model depicted above reinforces 
the importance of habitat conservation and management of threats to marine biodiversity. Although the model is simply linear, and employs very few variables, it nevertheless, provides a straightforward analysis of the importance of habitat protection. It also reinforces the importance of collective measures to prevent degradation of marine habitats that are home to $97 \%$ of global biodiversity. Ecosystem degradation is a gradual ongoing process; various factors contribute to degradation of marine habitats. So, effective monitoring is required to identify and protect keystone species. Given that the marine ecology provides ecosystem services, overexploitation of marine resources is an important issue to consider. In fact, overfishing has been implicated as the principle cause of decline of many species of fish, shellfish (Pauly et al. 2002, Rosenberg 2003), marine mammals, The coral ecology for example, is a source of rich and precious ecosystem services. However, corals are so sensitive to changes in temperature and salinity, that a rise in SST (Burke et al. 2001) of less than a few degrees centrigrade $\left(>1.1^{\circ} \mathrm{C}\right)$ leads to coral bleaching and ultimately causes death of corals ${ }^{7}$. Unusual rise in ocean water temperature (OWT) due to marked El Niño phenomenon has alarmed scientists who have observed intense coral bleaching event that is likely to extend well beyond 2017 (Ezzat and Courtial 2016). Rise in OWT or SST has been implicated to climate change which has threatened the future of the world's coral reefs (Guldberg 1999, Guldberg and Ridgway 2016). In a nutshell, almost all and every ecosystem are under threat; ie., equatorial, temperate, marine, estuarine, riverine, and freshwater ecosystems are reeling under stress from a multitude of anthropogenic activities. The coral bleaching event is not restricted to a single region; it spreads over three major ocean basins (Pacific, Atlantic and Indian). In fact, widespread "assault" on marine and terrestrial ecosystems have threatened global biodiversity. This paper attempts to analyze and understand the basis of threats to marine and aquatic ecosystems and reinforces the importance of habitat protection and conservation, as well as restoration of fragmented and

threatened habitats. Habitats of marine ecosystems are under threat, as well as the flora and fauna that flourishes under such habitats.

\section{Conclusion}

Loss of habitat threatens habitat specialists with extinction risk. The stress on major ecosystems has resulted in erosion of biodiversity due to various anthropogenic activites. The drivers of marine biodiversity loss have been enumerated in this paper. This was followed by an analytic model of ecosystem risks that depicts a simple representation of threats to marine biodiversity which reinforces the importance of biodiversity conservation and ecosystem protection. This research also attempts to open up debates and discussions on the importance of conservation management, and further points to new directions on this frontier.

\section{Acknowledgments.}

The author extends his thanks to the library staff of Dr. V.S. Krishna Central Library, Andhra University, for their kind assistance.

7. http://www.globalcoralbleaching.org 


\section{References}

- Appeltans, W., Ahyong, S. T., Anderson, G., Angel, M. V., Artois, T., Bailly, N., ... \& Błażewicz-Paszkowycz, M. (2012). The magnitude of global marine species diversity. Current Biology, 22(23), 2189-2202.

- Baillie, J.E.M., Hilton-Taylor, C. and Stuart, S.N. (Editors) 2004. 2004 IUCN Red List of Threatened Species. A Global Species Assessment. IUCN, Gland, Switzerland and Cambridge, UK.

- Boesch, D.F. 1999. The role of science in ocean governance. Ecol. Econ. 31: 189-198.

- Lauretta Burke, Yumiko Kura, Ken Kassem, Carmen Revenga, Mark Spalding, and Don McAllister. (2001). Pilot Analysis of Global Ecosystems: Coastal Ecosystems, World Resources Institute, Washington D.C.

- Cahill AE, Aiello-Lammens ME, Fisher-Reid MC, Hua X, Karanewsky CJ, Yeong Ryu H, Sbeglia GC, Spagnolo F, Waldron JB, Warsi O, Wiens JJ. 201 How does climate change cause extinction? Proc $R$ Soc $B$ 280: 20121890. http://dx.doi.org/10.1098/rspb.2012.1890

- Cardinale, B. J., Duffy, J. E., Gonzalez, A., Hooper, D. U., Perrings, C., Venail, P., ... \& Kinzig, A. P. (2012). Biodiversity loss and its impact on humanity. Nature, 486 (7401), 59-67.

- Casper, Kerr Julie. (2010). Changing Ecosystems: Effects of Global Warming. An imprint of Infobase Publishing.

- Conservation International. 2008. Economic Values of Coral Reefs, Mangroves, and Seagrasses: A Global Compilation. Center for Applied Biodiversity Science, Conservation International, Arlington, VA, USA.

- Cowling, R. M., Egoh, B., Knight, A. T., O'Farrell, P. J., Reyers, B., Rouget, M., ... \& Wilhelm-Rechman, A. (2008). An operational model for mainstreaming ecosystem services for implementation. Proceedings of the National Academy of Sciences, 105(28), 9483-9488.

- Craig, R. K. (2012). Marine biodiversity, Climate change, and governance of the oceans. Diversity, 4(2), 224-238.

- Díaz, S., Fargione, J., Chapin III, F. S., \& Tilman, D. (2006). Biodiversity loss threatens human well-being. PLoS Biol, 4(8), e277.

- Dobson, A., Lodge, D., Alder, J., Cumming, G. S., Keymer, J., McGlade, J., .. \& Wall, D. (2006). Habitat loss, trophic collapse, and the decline of ecosystem services. Ecology, 87(8), 1915-1924.

- Dulvy N.K., Y. Sadovy, and J.D. Reynolds. (2003). Extinction vulnerability in marine populations. Fish and Fisheries 4:25-64. 
- Dulvy, N. K., Fowler, S. L., Musick, J. A., Cavanagh, R. D., Kyne, M., Harrison, L. R., ... Sonja, V. (2014). Extinction risk and conservation of the world's sharks and rays, 1-34. doi:10.7554/eLife.00590

- Eakin CM et al. 2010 Caribbean corals in crisis: record thermal stress, bleaching, and mortality in 2005.PLoS ONE 5, e13969. (doi:10.1371/journal.pone.0013969)

- Eakin, C. M., Liu, G., Gomez, A., De la Cour, J., Heron, S., Skirving, W., ... \& Strong, A. (2016). Global coral bleaching 2014-2017: status and an appeal for observations. Reef Encounter, 31, 20-26.

- Estes, J. A., Burdin, A., \& Doak, D. F. (2016). Sea otters, kelp forests, and the extinction of Steller's sea cow. Proceedings of the National Academy of Sciences, 113(4), 880-885.

- Gonçalvesa, A. G., Ducattib, D. R., Duarteb, M. E. R., \& Nosedab, M. D. 5. (2014). Chemistry and biotechnology of phycocolloids.

- Glynn, P.W., 1991. Coral reef bleaching in the 1980's and possible connections with global warming. Trends in Ecological Evolution 6 (6), 175-179.

- Helm Dieter and Hepburn Cameron, (2014). Nature in the Balance: The Economics of Biodiversity, Oxford University Press.

- Hoegh-Guldberg O. and Ridgway T., (2016). Coral Bleaching Hits Great Barrier Reef As Global Temperatures Soar. Green Left Weekly,10.

- Hoegh-Guldberg, O., Hoegh-Guldberg, H., Veron, J.E.N., et al., (2009). The Coral Triangle and Climate Change: Ecosystems, People and Societies at Risk. WWF Australia, Brisbane.

- Hourigan, T. F. (1999). Conserving ocean biodiversity: Trends and challenges. Trends and Future Challenges for US National and Coastal Policy, 45-50.

- Hunter, CM., et al. (2010). Climate change threatens polar bear populations: a stochastic demographic analysis, Ecology, 91(10), 2010, pp.283-289.

- http://www.globalcoralbleaching.org/

- Hughes, T. P., Kerry, J. T., Álvarez-Noriega, M., Álvarez-Romero, J. G., Anderson, K. D., Baird, A. H., ... \& Bridge, T. C. (2017). Global warming and recurrent mass bleaching of corals. Nature, 543(7645), 373-377.

- Imtiyaz, B. B., Sweta, P. D., \& Prakash, K. K. (2011). Threats to Marine Biodiversity. Marine Biodiversity: Present Status and Prospects, 21-26.

- Jones, G. P., Srinivasan, M., \& Almany, G. (2007). Conservation of marine biodiversity. Oceanography (Washington, DC), 20, 100-111. 
- Joshi, K. K., Varsha, M. S., \& Sruthy, V. L. (2015). Marine Biodiversity of India-Status and Challenges.

- Keith, D. A., Rodríguez, J. P., Rodríguez-Clark, K. M., Nicholson, E., Aapala, K., Alonso, A., ... \& Benson, J. S. (2013). Scientific foundations for an IUCN Red List of Ecosystems. PLOS one, 8(5), e62111.

- Lefèvre, Julia Marton, (2007). Marine Protected Areas - governing our seas for the future. IUCN Report, European Newsletter, Vol. 13.

- Mapstone B, Appleford P, Broderick K, Connolly R, Higgins J, Hobday A, Hughes T, Marshall P, McDonald J, Waschka M, 2010: National Climate Change Adaptation Research Plan for Marine Biodiversity and Resources, National Climate Change Adaptation Research Facility, Gold Coast, 68pp.

- McClanahan, T. R., Ateweberhan, M., Muhando, C. A., Maina, J., \& Mohammed, M. S. (2007). Effects of climate and seawater temperature variation on coral bleaching and mortality. Ecological Monographs, $77(4)$, 503-525.

- McClenachan, L., Cooper, A. B., Carpenter, K. E., \& Dulvy, N. K. (2012). Extinction risk and bottlenecks in the conservation of charismatic marine species. Conservation Letters, 5(1), 73-80.

- Millennium Ecosystem Assessment (2005). Ecosystems and human well-being: biodiversity synthesis. World Resources Institute, Washington, DC.

- Marine Biodiversity Conservation Strategy, (2011). Chapter 5; Development of measures for conservation and sustainable use of marine biodiversity, pg. 34 Ministry of Environment Report, Japan.

- National Research Council (US); Avise JC, Hubbell SP, Ayala FJ, editors. In the Light of Evolution: Volume II: Biodiversity and Extinction. Washington (DC): National Academies Press (US); 2008. 3, Patterns of Biodiversity and Endemism on Indo-West Pacific Coral Reefs. Available from: https://www.ncbi.nlm.nih.gov/books/NBK214875/

- Nevill, J. (2008). Threats to marine biodiversity.

- Nunes, P. A., van den Bergh, J. C., \& Nijkamp, P. (2001). Ecologicaleconomic analysis and valuation of biodiversity.

- Nunes, Paulo A. L. D., \& Bergh, J. C. J. M. van den Bergh (2001). Economic valuation of biodiversity: sense or nonsense? Ecological Economics 39 (2001) $203-222$.

- Odum, E. P., Odum, H. T., \& Andrews, J. (1971). Fundamentals of ecology (Vol. 3). Philadelphia: Saunders.

- Ólafsson Emil (Ed.), (2017). Marine Macrophytes as Foundation Species. CRC Press, Taylor and Francis, ISBN 978-1-4987-2324-4. 
- Pan, J., Marcoval, M. A., Bazzini, S. M., Vallina, M. V., \& De Marco, S. G. (2013). Coastal marine biodiversity challenges and threats (pp. 43-67). Boca Raton, FL: CRC Press.

- Primack, R. B. (1993). Essentials of conservation biology (Vol. 23). Sunderland, Massachusetts: Sinauer Associates.

- Rodríguez JP et al. (2015) A practical guide to the application of the IUCN Red List of Ecosystems criteria. Phil. Trans. R. Soc. B370: 20140003. http://dx.doi.org/10.1098/rstb.2014.0003

- Rodríguez, J. P., RODRÍGUEZ-CLARK, K. M., Baillie, J. E., Ash, N., Benson, J., Boucher, T., ... \& Keith, D. A. (2011). Establishing IUCN red list criteria for threatened ecosystems. Conservation Biology, 25(1), 21-29.

- Rosenberg, A. A. (2003). Managing to the margins: the overexploitation of fisheries. Frontiers in Ecology and the Environment, 1(2), 102106.

- S F Heron, G Liu, J L Rauenzahn, T R L Christensen, W J Skirving, T F R Burgess, C M Eakin \& J A Morgan (2014) Improvements to and continuity of operational global thermal stress monitoring for coral bleaching, Journal of Operational Oceanography, 7:2, 3-11, DOI: 10.1080/1755876X.2014.11020154

- Sechrest, W. W., \& Brooks, T. M. (2002). Biodiversity-threats. eLS.

- Steele, J.H. 1998. Regime shifts in marine ecosystems. Ecol. Appl. 8: $33-36$.

- Tilman, D., Reich, P. B., \& Isbell, F. (2012). Biodiversity impacts ecosystem productivity as much as resources, disturbance, or herbivory. Proceedings of the National Academy of Sciences, 109(26), 10394-10397.

- Veron, J. E. N., Hoegh-Guldberg, O., Lenton, T. M., Lough, J. M., Obura, D. O., Pearce-Kelly, P., ... \& Rogers, A. D. (2009). The coral reef crisis: The critical importance of $<350 \mathrm{ppm}$ CO 2. Marine pollution bulletin, 58(10), 1428-1436.

- Walker, D. I., \& Kendrick, G. A. (1998). Threats to macroalgal diversity: marine habitat destruction and fragmentation, pollution and introduced species. Botanica marina, 41(1-6), 105-112.

- Wilson EO, Peter FM, editors. Biodiversity. Washington (DC): National Academies Press (US); 1988. Chapter 4, Ecological Diversity in Coastal Zones and Oceans. Available from: https://www.ncbi.nlm.nih.gov/books/NBK219271/

- Worm, B., Barbier, E. B., Beaumont, N., Duffy, J. E., Folke, C., Halpern, B. S., ... Selkoe, K. A. (2006). Impacts of Biodiversity Loss on Ocean Ecosystem Services. Science, Vol. 314 (November), 787-790.

- Worm et al. (2006). Recent biodiversity loss undermines ocean ecosystem services at all scales. Science 314: 787-790. 